\title{
Anatomic variability in the relation between the retromandibular vein and the facial nerve: a case report, literature review and classification
}

\author{
M. Piagkou1 ${ }^{1}$, M. Tzika², G. Paraskevas², K. Natsis² \\ ${ }^{1}$ Department of Anatomy, Medical School, National and Kapodistrian University of Athens, Greece \\ ${ }^{2}$ Department of Anatomy, Medical School, Aristotle University of Thessaloniki, Greece
}

[Received 5 April 2013; Accepted 24 May 2013]

\begin{abstract}
Knowledge of anatomic variations concerning head and neck veins is important to surgeons performing interventions in these regions, as well as to radiologists. The retromandibular vein is used as a guide to expose the facial nerve branches inside the parotid gland, during parotid surgery and open reduction of mandibular condyle fractures. It is also used as a landmark for localisation of the nerve and compartmentalisation of parotid gland lesions preoperatively, during computed tomography, magnetic resonance imaging and sonography. In this paper, the anomalous retromandibular vein's course on the left side of a male cadaver is described. The vein was formed around the nerve, while the maxillary vein travelled medial to the facial nerve branches and superficial to the superficial temporal vein. Interestingly, the facial nerve temporofacial division crossed again the superficial temporal vein upwards, forming a "nerve fork". The incidence of the reported variability of the relationship between the retromandibular vein and the facial nerve are discussed with a detailed literature review. Accordingly, the typical deep position of the retromandibular vein in relation to the facial nerve is estimated to $88.17 \%$ to all sides. Furthermore, an updated classification system is proposed, including 4 types and subtypes. (Folia Morphol 2013; 72, 4: 371-375)
\end{abstract}

Key words: retromandibular vein, facial nerve, variation, incidence, classification

\section{INTRODUCTION}

The retromandibular vein (RV) (temporomaxillary or posterior facial vein) has been reported as one of the anatomical landmarks that locate and protect the facial nerve (FN) during surgery $[3,19]$. The most important risk while intervening in the parotid gland is injuring the FN $[3,19]$. Consequently, location of the lesion in relation to the FN must be evaluated preoperatively in order to minimize the potential complications. As the direct visualising of the FN using imaging techniques is inefficient $[1,15,19]$, the RV can be used as a reliable landmark during magnetic resonance imaging (MRI) $[1,7,9]$, computed tomography (CT) scanning $[7,15]$ and sonography $[8]$ in order to identify the tumour location inside the parotid gland. Other anatomical landmarks, such as the Conn's arc [5], the Utrecht and the FN line $[1,15]$ could also be used, while the parotid duct criterion has been suggested additionally to the RV [9], assisting in the localisation of the parotid gland tumours, preoperatively.

The relationship of the two structures is also significant during surgical identification and preservation of FN branches. The FN could be traced after discovering the $\mathrm{RV}$ and following its course superiorly into the gland, until the crossing point with the inferior division of the nerve, although the nerve is expected 


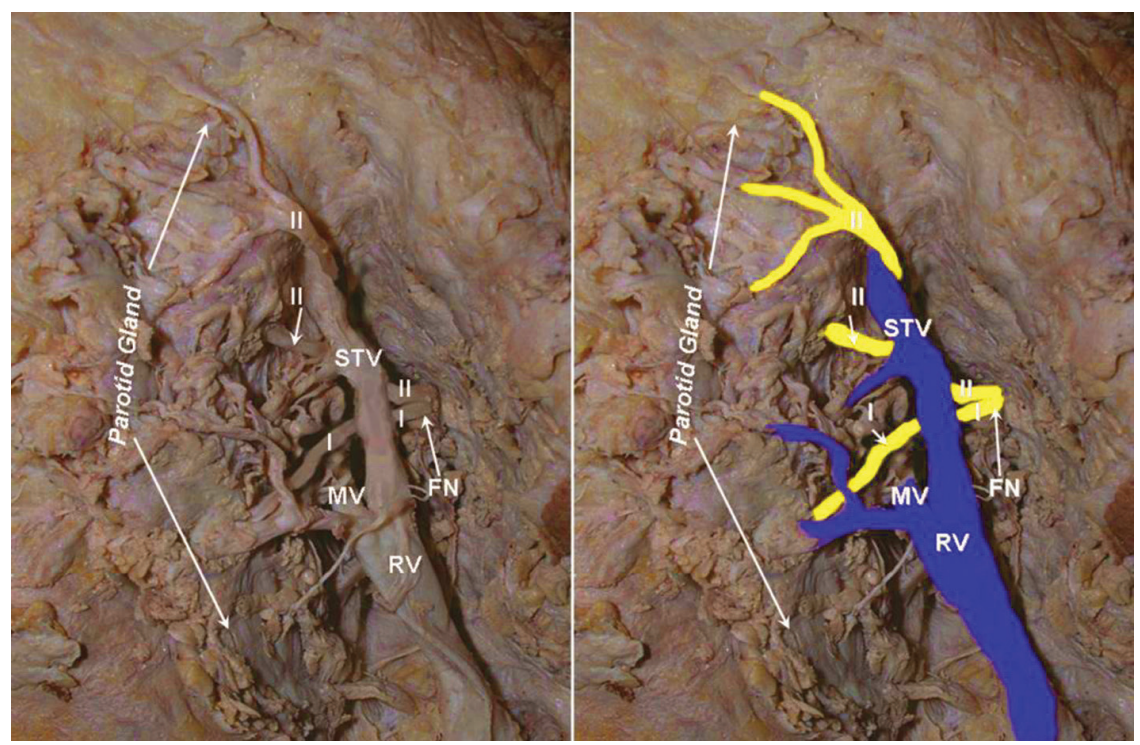

Figure 1. Anomalous relationship of the retromandibular vein (RV), the superficial temporal vein (STV) and the facial nerve (FN) on the left side of a male cadaver; MV — maxillary vein, I — cervicofacial division; II — temporofacial division.

to be found superficial to the vein. This method is especially recommended when parotid tumours are located posteriorly, between the mastoid process and parotid gland $[4,10]$. Additionally, RV and superficial temporal vein (STV) are used as landmarks for the protection of FN during superficial parotidectomy and open surgical reduction of mandibular condyle fractures $[3,10]$. Other landmarks have also been used for the intraparotid FN localisation, such as the mastoid process, the tragal pointer, the posterior belly of the digastric muscle and the tympanomastoid suture line $[3,4]$. Thus, thorough knowledge of the anatomy and possible variations of RV and STV is necessary in order to avoid FN damage during parotid surgery and operations around the mandibular angle.

Nevertheless, variations of the relationship between the RV and FN have been documented in the literature. These deviations from the expected topography of the intraparotid structures may have an important impact on surgical outcome, as the surgeon may not be aware of the existing variability. In this case report, a cadaveric case in which the RV was formed around the FN is described. Furthermore, an effort is made to review the existing variations in previously reported cases. The data was recorded, analysed and classified, thus the incidence, classification and clinical significance of these variations are finally discussed.

\section{CASE REPORT}

During the routine dissection of a formalin-fixed, Greek Caucasian cadaver, performed for educational purposes, a variant topographic relationship between the left RV and FN was encountered and captured by a digital camera. The 90-year-old male cadaver derived from the body donation with informed consent [16]. A pre-auricular incision was made, the parotid gland was carefully dissected and the nerves and vessels were exposed and examined. The course of RV was followed in order to discover the main trunk and divisions of FN inside the parotid gland. On the left side, the RV presented an anomalous course, as it was running superficial to the FN. The crossing point of the $\mathrm{RV}$ and FN was found slightly distal to the junction of STV and maxillary vein (MV) by which the left RV was formed. The MV lied deep to the divisions of FN, while STV was found superficial to the cervicofacial division. Noticeably, the STV travelled superficial to the first portion of the temporofacial division, while nerve branches crossed again the STV upwards, forming a "nerve fork" (Fig. 1). The right side did not present any variation, while no evidence of previous surgical procedures or pathological lesions were observed at the region.

\section{DISCUSSION}

As described in the classic anatomical textbooks, the STV, after crossing the posterior root of the zygo$\mathrm{ma}$, enters the parotid gland and unites with the MV to form the RV [18]. Antero-inferior to the mandibular angle, the anterior division of $\mathrm{RV}$ joins the facial vein $(\mathrm{FV})$, while the posterior division joins the posterior auricular vein forming the external jugular vein. Inside 
the parotid gland parenchyma, the RV crosses the FN, while the nerve typically lies superficial to the vein. Interestingly, the available literature data concerning the existing variations of the anatomy of RV and $F N$ is quite limited. Establishing the typical topography of the vein, some authors did not observe any variations regarding the anatomy of RV, as the cervicofacial FN division was found passing superficially to the RV in all the studied specimens $[14,17,20]$. The majority of the studies have investigated the marginal mandibular FN branches, while Lee [14] included in his study, the temporal FN branches too. Laing and McKerrow [13] in their 54 parotid gland dissections focused on the crossing between the divisions of $\mathrm{FN}$ and the branches of RV. The RV was always found in direct contact with the main FN trunk or its major divisions and in $68.5 \%$ of the cases, the distance between them was less than $5 \mathrm{~mm}$. In 5 cases, branches of the FN temporofacial division were found laterally to the MV, maintaining close contact with the RV. Only 1 case was encountered, in which the FN lower division lied deep to the RV.

On the contrary, some studies report that the RV topography in relation to $\mathrm{FN}$ may be different more usually than it is thought. In the study of Kopuz et al., [12] it was concluded that the RV lied medial to the FN temporofacial and cervicofacial divisions in $90 \%(45 / 50)$, and in $10 \%(5 / 50)$ the RV course was medial to the temporofacial and lateral to the cervicofacial divisions, whereas in a single case the RV was detected lateral to the nerve, at its bifurcation level. The authors also noticed that in $74 \%$ of the cases, the vein crossed the nerve at a level between the bifurcation and ramification points [12]. After examining 85 facial halves in cadavers, Kim et al. [11] observed lateral position of the FN cervicofacial division in relation to the vein in $83 \%$. From these cases, in $52 \%$ the nerve was divided into its branches after crossing the vein, whilst in 31\% the division occurred before the crossing point level. In the same study, the nerve was found medial to the vein in $17 \%$ of the cases, from which in $6 \%$ it divided after crossing the vein and in $11 \%$ before. No significant difference was found according to gender [11]. Additionally, Dingman and Grabb [6] noticed that the RV was located on the medial side of the mandibular branch of the FN in $98 \%(98 / 100)$ and lateral in $2 \%(2 / 100)$ of the specimens. The observed relationship between the RV and $\mathrm{FN}$ was classified in 6 types by Touré and Vacher [19]. The RV was found to be situated medial to the FN in the majority of the cases (Type 1,65.2\%, 86/132) and lateral to it in 28\% (Type 2, 37/132). Types 3 to 6 constituted subtypes of Type 2 . The RV was found lateral to the FN main trunk in $13.6 \%$ (Type $3,18 / 132$ ), to the cervicofacial division in 7.6\% (Type 4, 10/132), to the temporofacial division in 3\% (Type 5, 4/132) and to some of the cervicofacial FN branches in $3.8 \%$ (Type $6,5 / 132$ ). In the rest of the specimens, the RV or its branches were present on both sides of the FN trunk in $4.5 \%(6 / 132)$, of the cervicofacial division in $1.5 \%(2 / 132)$ and of the temporofacial division $(1 / 132)$ in $0.8 \%$. Furthermore, some cases of encountered variants have been reported in the literature independently [2-4]. Bhattacharyya and Varvares [4] observed a case, in which the inferior division of FN was encountered deep to the RV during parotid surgery, whereas cases in which the $\mathrm{FN}$ and its branches were found encircled by venous rings [19] or "forked" between the MV and its divisions have also been reported, found either during cadaver dissection or surgery $[2,3]$.

The aforementioned findings and the resulting incidences of the described relationship between RV and FN are presented in Table 1. The data concerns all cadaveric studies on the RV topography that have been documented and are available to us. It should be noted that all the limitations of the studies used are mentioned in the Table results. Consequently, the $\mathrm{RV}$ was found following the established as normal pattern, lying deep (medial) to the FN trunk or/and branches in $88.17 \%$, while in $11.83 \%$ the RV topography presented variability. The vein may be found lying anterior to the $\mathrm{FN}$, while it could be present bilaterally to the FN, either as a "ring" around the nerve branches or as a "fork" formed by the RV branches, as it occurs in our case $[2,3,19]$.

Based on Touré and Vacher's classification system [19] our case could not be included in any type, as the STV was encountered lying over both the FN divisions while the temporofacial branch crossed over the vein upwards. Additionally, all the reported cases of bilateral appearance of the RV in relation to the FN were not incorporated as separate types. Therefore, an updated classification system is suggested, where the $1^{\text {st }}$ type includes the typical deep position of RV, the $2^{\text {nd }}$ type the superficial position and the $3^{\text {rd }}$ and $4^{\text {th }}$ types the appearance of the vein on both sides of FN, thus venous rings and forks, respectively (Fig. 2). Every type contains subtypes that correspond to different 
Table 1. Incidence of the reported relationship between the RV and FN. The variant position is noted, including the separate case reports

\begin{tabular}{|c|c|c|c|c|c|c|}
\hline Author & Year & Country* & Specimen & $\begin{array}{l}N \text { (facial } \\
\text { halves) }\end{array}$ & $\begin{array}{l}\text { RV deep/medial to the FN } \\
\text { (typical position) }\end{array}$ & Variant(s) \\
\hline $\begin{array}{l}\text { Dingman } \\
\text { and Grabb [6] }\end{array}$ & 1962 & USA & Cadaveric & 100 & $\begin{array}{l}98 \text { ( } 98 \% \text { of the mandibular } \\
\text { FN branches) }\end{array}$ & $\begin{array}{l}2(2 \% \text { of the mandibular } \\
\text { FN branches) }\end{array}$ \\
\hline Lee [14] & 1987 & Korea & Cadaveric & 54 & $\begin{array}{c}54 \text { (100\% of the cervicofacial } \\
\text { FN division) }\end{array}$ & - \\
\hline $\begin{array}{l}\text { Laing and } \\
\text { McKerrow [13] }\end{array}$ & 1988 & UK & Cadaveric & 54 & $48(88.9 \%)$ & $\begin{array}{c}5(9.3 \%) \rightarrow \text { MV lying lateral to branches } \\
\text { of the temporofacial division } \\
1(1.8 \%) \rightarrow \text { lateral to FN } \\
\text { cervicofacial division }\end{array}$ \\
\hline Wang et al. [20] & 1991 & China & Cadaveric & 120 & $\begin{array}{c}120(100 \% \text { of the mandibular } \\
\text { FN branches) }\end{array}$ & - \\
\hline Kopuz et al. [12] & 1995 & Turkey & Cadaveric & 50 & $45(90 \%)$ & $\begin{array}{l}5(10 \%) \rightarrow \text { lateral to the lower FN trunks } \\
\text { and medial to the upper FN trunks }\end{array}$ \\
\hline Savary et al. [17] & 1997 & France & Cadaveric & 22 & $\begin{array}{c}22(100 \% \text { of the mandibular } \\
\text { FN branches) }\end{array}$ & $\begin{array}{l}- \\
\text { (Note: anastomosis between the } \\
\text { mandibular and cervical FN branches } \\
\text { lateral to the RV) }\end{array}$ \\
\hline Kim et al. [11] & 2009 & Korea & Cadaveric & 85 & $\begin{array}{c}71 \text { (83\% of the cervicofacial } \\
\text { FN division) }\end{array}$ & $\begin{array}{c}14(17 \%) \rightarrow \text { FN cervicofacial division } \\
\text { crossing medially the RV }\end{array}$ \\
\hline $\begin{array}{l}\text { Touré and } \\
\text { Vacher [19] }\end{array}$ & 2010 & France & Cadaveric & 132 & $86(65.2 \%)$ & $\begin{array}{c}37(28 \%) \rightarrow \text { lateral to the FN trunk } \\
\text { or divisions } \\
9(6.8 \%) \rightarrow \text { bilaterally to the FN } \\
\text { Total: } 46(34.8 \%)\end{array}$ \\
\hline Total & & & & 617 & $544(88.17 \%)$ & $73(11.83 \%)$ \\
\hline $\begin{array}{l}\text { Bhattacharyya } \\
\text { and Varvares [4] }\end{array}$ & 1999 & USA & Surgical & $\begin{array}{l}1 \text { case } \\
\text { report }\end{array}$ & & $\mathrm{RV}$ medial to FN \\
\hline Astik et al. [2] & 2011 & India & Cadaveric & $\begin{array}{l}1 \text { case } \\
\text { report }\end{array}$ & & $\begin{array}{c}\text { FN "forked" } \\
\text { between MV and STV }\end{array}$ \\
\hline $\begin{array}{l}\text { Babademez } \\
\text { et al. [3] }\end{array}$ & 2012 & Turkey & Surgical & $\begin{array}{l}1 \text { case } \\
\text { report }\end{array}$ & & $\begin{array}{l}\text { FN cervicofacial division "forked" } \\
\text { between the MV and STV }\end{array}$ \\
\hline
\end{tabular}

${ }^{*}$ Of origin of the study; RV — retromandibular vein; FN — facial nerve; STV — superficial temporal vein; MV — maxillary vein

\section{Classification of the variant topography of FN-RV}

\section{Type I}

(a)

Type II

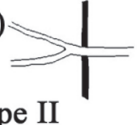

(b)

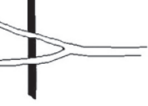

(a)

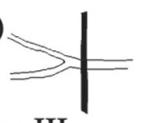

(b)

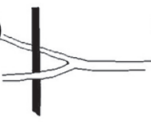

(c)

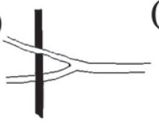

(d)

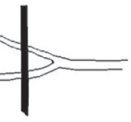

(a)<smiles>COC(C)(C)C</smiles>

(b)

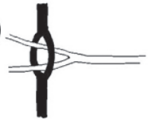

(c)

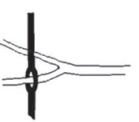

(d)

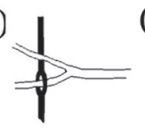

(e)

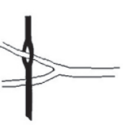

(f)

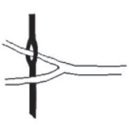

Type IV
(a) 1
(b)

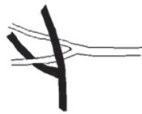
(c)
(d)

Figure 2. An updated classification system is proposed, describing the variant relationship between the retromandibular vein (RV) and facial nerve (FN). The bifurcated white scheme corresponds to the FN trunk and its superior and inferior divisions (up and down, respectively), while the black collared scheme refers to the RV and its branches. Note that in the type IV, the mainly deep division of the RV is the maxillary vein and the superficial division, the superficial temporal vein; the two veins converge and form the RV. 
variants; for example, the case report of Babademez et al. [3] presents a variant RV that could be characterised as Type IV(d), the variant described by Astik et al. [2] could be included in Type IV(b), whilst our case is a combination of Type IV(b) and Type IV(d). We should however highlight that in the Type III, only cases (a) and (c) have been reported in the literature [19].

As it is described, the classical relationship between the vein and FN may not be observed as often as it is believed. Nevertheless, as it occurs in the present review, variations appear in a respectable incidence of $11.83 \%$, while the FN-RV topography could be classified in 4 separate main types. Thus, surgeons should keep in mind that RV always lies in close proximity to the nerve, but the relationship between them may vary. In the present case report, the RV branches "forked" the FN divisions, while the STV covered a part of the FN branches. This unexpected position of the veins might lead to postsurgical complications, as the superficially located RV is susceptible to bleeding, increasing the risk of FN injury [3]. The knowledge of the potentially variant position of FN is important during surgery in the area in order to prevent unexpected FN injury or bleeding.

\section{REFERENCES}

1. Ariyosh, Y, Shimahara M (1998) Determining whether a parotid tumour is in the superficial or deep lobe using magnetic resonance imaging. J Oral Maxillofac Surg, 56: 23-26.

2. Astik RB, Dave UH, Gajendra KS (2011) Variant position of the facial nerve in parotid gland. Int J Anat Var, 4: 3-4.

3. Babademez MA, Acar B, Gunbey E, Karabulut H, Karasen RM (2012) Anomalous relationship of the retromandibular vein to the facial nerve as a potential risk factor for facial nerve injury during parotidectomy. J Craniofac Surg, 21: 801-802.

4. Bhattacharyya N, Varvares MA (1999) Anomalous relationship of the facial nerve and the retromandibular vein: a case report. J Oral Maxillofac Surg, 57: 75-76.

5. Conn IG, Wiesenfeld D, Ferguson MM (1983) The anatomy of the facial nerve in relation to $\mathrm{CT} /$ sialography of the parotid gland. Br J Radiol, 56: 901-905.

6. Dingman RO, Grabb WC (1962) Surgical anatomy of the mandibular ramus of the facial nerve based on the dissection of 100 facial halves. Plast Reconstr Surg Transplant Bull, 29: 266-272.
7. El-Hakim H, Mountain R, Carter L, Nilssen EL, Wardrop P, Nimmo M (2003) Anatomic landmarks for locating parotid lesions in relation to the facial nerve: cross-sectional radiologic study. J Otolaryngol, 32: 314-318.

8. Howlett DC (2003) High resolution ultrasound assessment of the parotid gland. Br J Radiol, 76: 271-277.

9. Imaizumi A, Kuribayashi A, Okochi K, Ishii J, Sumi $Y$, Yoshino N, Kurabayashi T (2009) Differentiation between superficial and deep lobe parotid tumours by magnetic resonance imaging: usefulness of the parotid duct criterion. Acta Radiol, 50: 806-811.

10. Kawakami S, Tsukada S, Taniguchi W (1994) The superficial temporal and retromandibular veins as guides to expose the facial nerve branches. Ann Plast Surg, 32: 295-299.

11. Kim DI, Nam SH, Nam YS, Lee KS, Chung RH, Han SH (2009) The marginal mandibular branch of the facial nerve in Koreans. Clin Anat, 22: 207-214.

12. Kopuz C, llgi S, Yavuz S, Onderoğlu S (1995) Morphology of the retromandibular vein in relation to the facial nerve in the parotid gland. Acta Anat (Basel), 152: 66-68.

13. Laing MR, McKerrow WS (1988) Intraparotid anatomy of the facial nerve and retromandibular vein. Br J Surg, 75: 310-312.

14. Lee JW (1987) Surgical anatomy of the temporal branch and marginal mandibular branch of the facial nerve based on the dissection of 54 facial halves. The Graduate School, Yonsei University, Seoul [doctoral dissertation].

15. Lim CY, Chang HS, Nam KH, Chung WY, Park CS (2008) Preoperative prediction of the location of parotid gland tumors using anatomical landmarks. World J Surg, 32: 2200-2203.

16. McHanwell S, Brenner E, Chirculescu ARM, Drukker J, van Mameren H, Mazzotti G, Pais D, Paulsen F, Plaisant O, Caillaud MM, Laforet E, Riedere BM, Sanudo JR, Bueno-Lopez JL, Donate-Oliver F, Sprumont P, Teofilovski-Parapid G, Moxham BJ (2008) The legal and ethical framework governing Body Donation in Europe: a review of current practice and recommendations for good practice. Eur J Anat, 12: 1-24.

17. Savary V, Robert R, Rogez JM, Armstrong O, Leborgne J (1997) The mandibular marginal ramus of the facial nerve: An anatomic and clinical study. Surg Radiol Anat, 19: 69-72.

18. Standring S, Borley NR, Collins P, Crossman AR, Gatzoulis MA, Healy JC eds. (2008) Gray's anatomy: the anatomical basis of clinical practice. $40^{\text {th }}$ Ed. Elsevier, Churchill Liwingstone London.

19. Touré $G$, Vacher C (2010) Relations of the facial nerve with the retromandibular vein: anatomic study of 132 parotid glands. Surg Radiol Anat, 32: 957-961.

20. Wang TM, Lin CL, Kuo KJ, Shih C (1991) Surgical anatomy of the mandibular ramus of the facial nerve in Chinese adults. Acta Anat (Basel), 142: 126-131. 